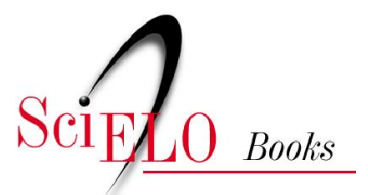

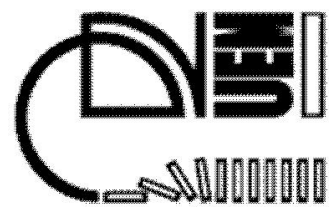

\title{
Identidades do masculino no humor
}

\author{
Adélli Bortolon Bazza \\ Maria Célia Cortez Passetti
}

SciELO Books / SciELO Livros / SciELO Libros

BAZZA, AB., and PASSETTI, MCC. Identidades do masculino no humor. In TASSO, I., and NAVARRO, P., orgs. Produção de identidades e processos de subjetivação em práticas discursivas [online]. Maringá: Eduem, 2012. pp. 209-229. ISBN 978-85-7628-583-0. Available from SciELO Books $<$ http://books.scielo.org $>$.

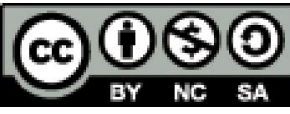

All the contents of this chapter, except where otherwise noted, is licensed under a Creative Commons Attribution-Non Commercial-ShareAlike 3.0 Unported.

Todo o conteúdo deste capítulo, exceto quando houver ressalva, é publicado sob a licença Creative Commons Atribuição Uso Não Comercial - Partilha nos Mesmos Termos 3.0 Não adaptada.

Todo el contenido de este capítulo, excepto donde se indique lo contrario, está bajo licencia de la licencia Creative Commons Reconocimento-NoComercial-CompartirIgual 3.0 Unported. 


\section{IDENTIDADES DO MASCULINO NO HUMOR}

Adélli Bortolon Bazza ${ }^{38}$, Maria Célia Cortez Passetti ${ }^{39}$

Os confrontos e disputas por espaço entre o gênero masculino e o gênero feminino parecem algo bastante comum e existente há muito tempo. Diferentes documentos, textos e figuras de diversas épocas oferecem-nos informações sobre a atribuição de papéis a cada gênero em determinada cultura, lugar e/ou tempo. Esses textos constituem discursos sobre o que é ser homem e o que é ser mulher, mostrando que essas relações foram e são tensas.

Ao relacionar esses discursos podemos perceber certas regularidades, como a recorrência de práticas que constituem discursos machistas, feministas, igualitários e outros; mas ocorrem também deslocamentos, possibilitando a irrupção de um novo discurso. Entre os recentes deslocamentos observados no campo do gênero destaca-se o surgimento do chamado "novo homem"40, o que culminou na constituição de uma nova identidade para o masculino. A chegada dessa nova identidade,

38 Doutoranda do Programa de Pós-Graduação em Letras da UEM.

39 Professora do Departamento de Letras e do Programa de Pós-Graduação em Letras da UEM.

40 Bonácio, neste volume, aprofunda a reflexão sobre as práticas e os discursos que contribuem para o surgimento dessa identidade de masculino. 


\begin{abstract}
Produção de identidades e processos de subjetivaçäo em práticas discursivas
como qualquer mudança, trouxe incômodos, discussões e inquietações. Uma das grandes dificuldades estava em delimitar quais seriam os elementos, as práticas, as crenças que compunham essa identidade. Ao contrário da postura machista, com a qual as pessoas conviveram por muito tempo e da qual já havia se instaurado uma memória, o "novo homem" ainda tinha/tem sua identidade em construção.

A mídia tem contribuído bastante para a instauração da identidade desse "novo homem" ao fazer circular inúmeros textos abordando o assunto. Textos que parecem ser puramente informativos ou jocosos criam propostas de identidades para esse "novo homem" e as fazem atingir homens e mulheres. Neste artigo selecionamos como objeto de análise um texto produzido pela mídia televisiva, com o intuito de observar como as identidades de masculino são representadas e como se pode criar o humor a partir delas. Trata-se do programa "Sexo Frágill", exibido pela Rede Globo no ano de 2003, sob a forma de seriado humorístico. Algumas peculiaridades justificam a escolha desse programa, entre elas o fato de ser veiculado pela televisão, um dos mais difundidos meios de comunicação no Brasil, e a sua proposta de ridicularização dos homens ao retratá-los como sexo frágil.
\end{abstract}

\title{
Criar, discutir e rir das identidades
}

Falar desse "novo homem" compreendendo-o como uma identidade de masculino implica pensar o contexto para o surgimento dessa e de outras identidades. Apesar de este tema ser discutido há algum tempo, a identidade e assuntos a 
ela relacionados têm recebido acentuada atenção dentro das discussões, quando associada ao Pós-Modernismo e seus efeitos.

Teóricos filiados aos chamados Estudos Culturais têm apontado alguns dos sintomas dessa fase. O Pós-Modernismo implica o questionamento das verdades dadas a priori, a multiplicação e a simultaneidade de informações, eventos e ideias e a velocidade com que as coisas são criadas, mudadas ou descartadas, tudo isso culminando numa constante provisoriedade que atinge também as noções sobre o que é "ser" hoje.

Hall (1997) mostra as mudanças que contribuíram para o declínio da representação do sujeito moderno e a instauração de outro, o sujeito pós-moderno. De acordo com autor, há cinco grandes 'descentramentos' que incidem nesse sujeito cartesiano: 1)- o pensamento marxista, que compreende o sujeito como fruto de um contexto; 2)- a descoberta do inconsciente, a qual mostra que o sujeito não domina tudo que pensa e faz; 3)- a concepção de língua de Saussure, que recusou as escolhas individuais na fala ao considerar a língua um sistema negociado na sociedade; 4)- o sujeito de Foucault, que é fruto de uma dispersão de discursos; e 5)- o feminismo.

De acordo com o autor, o feminismo questionou a distinção entre dentro e fora, público e privado enfatizou a forma como somos constituídos como sujeitos, colocou em questionamento a concepção de homens e mulheres como parte de uma única identidade e propôs a questão da diferença sexual.

É a partir da tendência do pensamento feminista calcado na diferença que se desenvolve melhor esse pensamento e se chega à compreensão de que o 
Produçäo de identidades e processos de subjetivaçäo em práticas discursivas

"masculino" e o "feminino" são criações culturais e, como tal, são comportamentos apreendidos através do processo de socialização que condiciona diferentemente os sexos para cumprirem funções sociais específicas e diversas. Essa aprendizagem é um processo social. Aprendemos a ser homens e mulheres e aceitar como "naturais" as relações de poder entre os sexos (ALVES; PITANGUY, 1985, p. 55).

É a partir dessa perspectiva que se começa a questionar os conceitos de homem e de mulher e também os de masculino e o feminino. Desde o momento em que esses conceitos começam a ser pensados como fruto de um processo que se dá no e pelo meio social, passa-se a trabalhar com o conceito de gênero.

Reflexões dessa natureza desencadearam a reestruturação das identidades, culminando, entre outras propostas, na de identidade para o "novo homem". Esse não é um processo tão simples assim, pois, ao mesmo tempo em que há grupos ávidos por mudanças, há também bastante resistência. Destarte a discussão se apresenta de forma sutil, e muitos textos que abordam essa temática se caracterizam por certa leveza, certa graça, que muitas vezes é obtida através do humor. Essa relação também não parece ser fortuita...

É notória a frequência com que no humor se abordam temas controversos. Parece haver uma moratória social que permite que por meio do humor se trate de temas e/ou se assumam posicionamentos socialmente polêmicos sem que as pessoas sejam punidas pelos gracejos que produzem. Isso possibilita que em nossa sociedade o humor se constitua como um lugar de contestação de valores sem que quem dele participe sofra alguma sanção. Possenti $(2000$, p. 82$)$ formula essa ideia ao afirmar que "rimos da subversão dos valores". Diante disso, pareceu-nos interessante observar a discussão sobre a reestruturação das 
identidades dos gêneros, especificamente da do "novo homem", em um texto de natureza humorística.

Saliba (2002) considera que o humorismo seria uma reflexão que transforma aquilo que nos é familiar, que poderia ter acontecido conosco em algo estranho a nós. Esse estranhamento do humor possibilita-lhe o caráter desmistificador, mas o leva a um território de fragmentação e mudanças, ou seja, aquilo que se produz em humor não se repete ad infinitum, pelo contrário, tende a caducar logo, pois os alvos do humor são seres históricos, produzidos socialmente portanto, igualmente mutáveis.

Em função desse caráter sócio-histórico do humor, algumas questões são motivadas pela ocorrência do programa Sexo Frágil: o fato de ter sido possível fazer humor acerca de um novo (ou velho?) tipo de homem pode indicar que a representação da identidade de masculino tradicional como única e homogênea já foi atingida por essas reconfigurações pós-modernas e que estamos, no mínimo, diante de duas possibilidades de identidade de masculino: o velho (forte?) e o novo (frágil?). Essas possibilidades se multiplicam quando se leva em conta o fato de as identidades não serem homogêneas, estanques e acabadas, mas heterogêneas, interligadas e sempre negociadas.

A observação de alguns recursos causadores do efeito humorístico pode ajudar a compreender os movimentos de identificação e desidentificação criados nesse discurso. A primeira questão envolve as implicações sociais do riso, que Bergson (1983) considera como uma espécie de correção social da rigidę mecânica dos sujeitos. É como se a situação requeresse determinada habilidade e flexibilidade que ela não teve e de cuja falta se risse. 
Produçäo de identidades e processos de subjetivaçäo em práticas discursivas

Nessa perspectiva, o riso é confirmado como uma forma de castigar os costumes, pois, assim como as coisas mudam,

a sociedade há de querer um esforço constante de adaptação recíproca [dos indivíduos]. Toda rigidez do caráter, do espírito e mesmo do corpo, será, pois, suspeita à sociedade [...]. Ela está diante de algo que a inquieta, mas a título de sintomas apenas - simplesmente ameaça, no máximo um gesto. E, portanto, por um simples gesto ela reagirá. $\mathrm{O}$ riso deve ser algo desse gênero: uma espécie de gesto social (BERGSON, 1983, p. 19).

No caso de Sexo Frágil, a rigidez é um dos motes desencadeadores do riso no programa. Apresentadas com o objetivo de ridicularizar o homem, as situações cômicas vividas por esses quatro rapazes devem-se à inadequação desses personagens às diversas situações vividas por eles na sociedade atual, principalmente no que toca às suas relações com as mulheres ou com áreas em que a mudança promovida pela revolução feminista requeira adaptações.

Outro mecanismo de criação do humor presente no programa é a paródia. Descrevendo-a à esteira do dialogismo bakthiniano, Sant'Anna (2002) a considera um texto polifônico, porque nele se podem perceber várias vozes. Não obstante, o autor (SANT'ANNA, 2002, p. 14) ressalta que "as vozes na paródia não são apenas distintas e emitidas de uma para outra, mas se colocam, de igual modo, antagonisticamente". Esse antagonismo, por um lado, evidencia a oposição entre masculino e feminino, ressaltando a polêmica instaurada entre os diferentes posicionamentos; e por outro, descentra e, assim, destrona, ridiculariza a pretensa identidade una e homogênea do sujeito masculino. 
Terceira parte :: Identidades do masculino no humor

\section{Analisar as identidades discursivas}

Devido à heterogeneidade que atravessa a discurso e, consequentemente as identidades nele produzidas, torna-se difícil descrever uma identidade de masculino assumida pelos personagens do programa. Descrever essa identidade é, em última instância, descrever o processo de identificação do(s) sujeito(s) analisado(s) com as demais identidades, com os demais discursos, com as memórias que cada um deles atualiza.

Dessa maneira, a análise inscreve-se no campo discursivo a partir do conceito de 'identidade de posicionamento'. Isso quer dizer que pretendemos discutir a identidade a partir da "posição que o sujeito ocupa em um campo discursivo em relação aos sistemas de valores que aí circulam" (CHARAUDEAU; MAINGUENEAU, 2004, p. 267). Para tanto, buscaremos a identidade do sujeito masculino representada no programa Sexo Frágil pela rede de relações discursivas estabelecida entre sujeitos masculinos e femininos desse programa, tentando identificar a posição-sujeito que esses homens assumem ou que lhe é delegada na prática discursiva humorística.

Pensar essa rede de relações discursivas implica abordar a heterogeneidade que constitui os sujeitos (personagens do programa) e os discursos que eles suportam. Muitas vezes, em casos de citações e de discursos diretos e discursos indiretos, a presença do discurso Outro é marcada como constituinte do que Authier-Revuz (1982) denominou heterogeneidade mostrada 'marcada', embora haja momentos em que essa cisão entre o discurso Mesmo e o Outro não é tão evidente, como no caso do humor, em que um "outro dizer" é retomado para produzir sentido, mas não necessariamente é explicitado. 

seu sistema de valores, criando dele 'simulacros'. É por isso que Maingueneau (2007, p. 103) afirma que

esses enunciados do Outro só são "compreendidos" no interior do fechamento semântico do intérprete; para constituir e preservar sua identidade no espaço discursivo, o discurso não pode haver-se com o Outro como tal, mas somente com o simulacro que constrói dele.

Por estarem em concorrência dentro do campo discursivo, esses discursos polemizam entre si, trabalhando na incessante tentativa de estabelecer sua identidade a partir da nega(tiviza) ção do seu Outro. Para o Maingueneau (2007, p. 110), “manter a própria identidade e definir a priori todas as figuras que o Outro pode assumir são uma e só coisa". A identidade de masculino criada a partir da Formação Discursiva (FD) machista se constrói com a noção de oposição: assim como estão opostos semas positivados e negativados, opõem-se os gêneros (masculino e feminino). A identidade então se fecha por conta da identificação de si aos semas positivos e pela impossibilidade de seu outro (sujeito feminino) e Outro (discurso feminino) se identificarem a esses semas positivos.

Pretendemos analisar os traços/semas que constituem o sujeito masculino do programa Sexo Frágil, tratando a polêmica com o discurso feminino como fator de desestabilização, descentramento e criação de humor sobre esse sujeito e sua identidade; ou seja, queremos apreender, como propõe Maingueneau, a rede de relações interdiscursivas na qual esse discurso se constitui. Por tratarmos da oposição entre os gêneros, oporemos a FD machista à FD igualitária, pois, principalmente nos últimos anos, o feminismo tem proposto a igualdade entre os gêneros, em contraposição à ideia radical de superioridade de 
um sobre o outro. Esse ideal de convivência parece-nos ter se configurado como o verdadeiro ${ }^{41}$ dessa época.

\section{A identidade do "novo homem" em questão}

Para analisar quais identidades foram construídas para o masculino nesse programa, selecionamos uma cena em que os amigos, reunidos em um bar, relatam problemas que vêm enfrentando em seu dia a dia como resultado da convivência com as mulheres e buscam definir um lugar para si mesmos nessa cadeia de eventos ${ }^{42}$. Esta cena faz parte do nono programa, intitulado "Para que serve um homem?". Nela interagem os personagens Edu, representado por Vagner Moura, e Alex, representado por Bruno Garcia. Posteriormente, a Edu e Alex se juntam Fred, representado por Lázaro Ramos, e Beto, representado por Lucio Mauro Filho.

Nesse programa Alex trabalha em uma fábrica de lingerie e está concorrendo a uma vaga de gerente geral da empresa, mas perde a vaga para uma colega de trabalho. Edu chega a sua casa de uma viagem trazendo flores para a esposa, Malu, e a encontra na cama com outra. Fred, que é jornalista, perde uma reportagem

41 Empregamos esse termo a partir da noção foucaultiana de que uma série de discursos apresenta um mesmo saber e esse se estabelece como verdade para um grupo e em um momento determinado. Cf. Foucault (1999).

42 A cena analisada neste artigo faz parte do corpus de nossa dissertação de mestrado. Por isso, muitas das asserções aqui levantadas estão fundamentadas em observações das demais cenas analisadas durante a pesquisa. Para uma compreensão mais ampla do tema, cf. BAZZA, A. B. Identidade(s) do sujeito masculino no programa humorístico Sexo Frágil. 2009. 112f. Dissertação de Mestrado (Mestrado em Letras) Centro de Ciências Humanas Letras e Artes. Universidade Estadual de Maringá, Maringá, 2009. 
para uma colega de trabalho e ainda apanha dela. Beto, que está separado de Vilminha, não consegue realizar consertos em encanamentos do apartamento para agradar e tentar reconquistar a mulher.

No original do programa esta cena era bastante extensa. Para adaptá-la e adaptar sua análise a este texto, foi suprimido um trecho de seu meio. Trata-se do momento em que Beto e Fred chegam ao bar e contam seus problemas. Essa supressão os comentários sobre a cena são marcados dentro do quadro de transcrição por letra em itálico.

\begin{tabular}{l}
\multicolumn{1}{|c|}{ Trilha sonora } \\
Bar onde seria a festa de Alex, decorado com bexigas \\
e faixas com dizeres "Alex o chefe do ano". Alex, \\
sożinho, bebe e fuma. Edu chega \\
Cantor canta música: Eu não sou cachorro não, \\
pra viver tão humilhado, eu não sou cachorro \\
não, para ser tão desprezado. \\
Edu: Alex, uma desgraça aconteceu. \\
Alex: Minha promoção no trabalho dançou. \\
Edu: Então foram duas. \\
Alex: Você perdeu a promoção também? \\
Edu: Não, não, não. Foram duas desgraças. \\
(senta-se) Eu perdi a Malu. \\
Alex: Só? Eu perdi a gerência inteira. \\
Edu: Promoveram outro? \\
Alex: Pior, promoveram outra. Eu vou ter uma \\
chefe mulher.
\end{tabular}


Edu: Mas essas mulheres tão tomando conta de tudo, gente.

Alex: A Malu também te trocou por outro?

Edu: Pior, por outra.

Alex: Que isso?

Edu: E o nome da pessoa é Ricardinha. Agora nós estamos competindo pra ver quem vai ficar com a Malu.

Alex: E o que é que você tá fazendo aqui? Quer acabar perdendo a Malu por WO?

Edu: Não, eu pensei em te pedir umas dicas, assim... sobre a superioridade dos homens em relação às mulheres, mas eu acho que não foi uma boa ideia.

Beto e Fred também chegam e desabafam sobre seus problemas.

Edu: A verdade é uma só, gente: nós somos o chamado sexo frágil.

Alex: Elas estão no poder.

Beto: No comando.

Fred: Os números comprovam: as mulheres vivem $30 \%$ a mais que os homens.

Edu: Elas odeiam rachar a conta do restaurante. Alex: Elas adoram ir ao banheiro em turma.

Beto: Elas se depilam com o nosso aparelho de barbear.

Fred: Pior: elas fingem orgasmo.
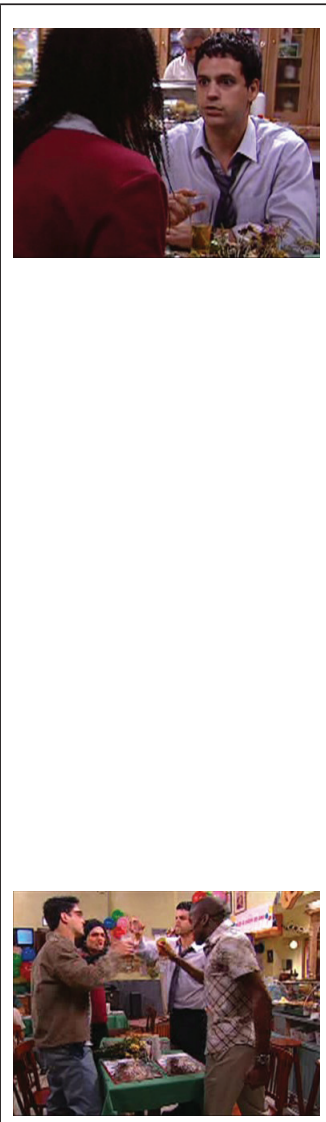
Terceira parte :: Identidades do masculino no humor

Edu: Fingem orgasmo.

Alex: Fingem orgasmo.

Beto: Quase sempre fingem orgasmo.

Alex: Tá cada vez mais difícil fazer uma mulher feliz.

Música: E o nosso amor, pelo amor de Deus, eu não sou cachorro não.

Edu: A gente tem valor.

Edu: Eu vou mostrar pra Ricardinha que os homens são muito superiores às mulheres. A Malu será minha! Minha!

Beto: A Vilminha não vai acreditar de tanta privada que eu vou desentupir, de tanta lâmpada que eu vou trocar.

Alex: Eu vou provar pra minha chefe que eu sou melhor que ela. No final ela vai acabar me promovendo a chefe dela mesma.

Fred: É!!!!

Os quatro: Viva os homens!!!!!!

(Barulho de tiro, todos gritam e sobem nas cadeiras, apavorados).

Havia sido combinada uma festa no bar para comemorar o aniversário de Alex. Essa cena inicia-se com Alex sentado sozinho à mesa. Edu chega ao bar desesperado, pois acabara de flagrar sua mulher com outra, fato que ele denomina "uma desgraça", indicando a importância que ele dá ao que aconteceu. Alex, sem saber dos problemas pessoais do amigo, desabafa, dizendo a Edu que sua promoção no trabalho não acontecera. 


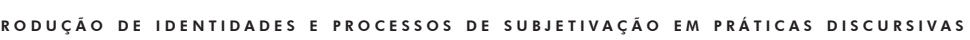

A fala de Alex minimiza o problema de Edu, ao dizer: "Só? Eu perdi a gerência inteira". Isso demonstra a valorização do trabalho em oposição aos problemas sentimentais. Mais que um possível egoísmo de Alex, localiza-se aí uma identificação ao discurso machista, retomando-se o ideal de masculinidade atrelado ao racional, em oposição à consideração do sentimento como um campo feminino.

Com isso Alex identifica-se à FD machista, mas sua identidade de macho está descentrada pelos fatos vividos pelo personagem: a promoção de uma mulher em seu lugar. A natureza humorística desse discurso é um dos fatores que permitem que o personagem Alex identifique-se a um discurso tão tipicamente machista, pois o discurso que predomina atualmente na sociedade é o da igualdade.

Como toda identidade se marca pela afirmação do eu simultaneamente à negação do outro, e ao mesmo tempo associa o racionalismo à identidade de homem macho que cria, Alex denega o discurso sentimental e a preocupação com o relacionamento, que, segundo seu sistema de valores, caracteriza seu par oposto na vida (a mulher) e o discurso com o qual ele polemiza, o feminismo. A primeira identidade de homem delineada e assumida no discurso da cena é a do homem machista, que apresenta um discurso ainda bastante característico, mas é descentrado pelos fatos de seu dia a dia e confrontado com a necessidade de nova(s) identidade(s).

$\mathrm{Na}$ realidade, o que preocupa Edu é o que ele sente no âmbito do seu relacionamento amoroso com Malu. Com isso ele assimila à sua identidade o sentimentalismo que Alex denega para delimitar a dele, e juntamente com ela, surgem traços de identificação com a FD machista. 
Ao perguntar se promoveram 'outro', Edu verbaliza a pressuposição de que o chefe seria um sujeito do sexo masculino, discurso que se atrela ao ideal de masculinidade comentado acima, o qual, por representar o homem como o gênero racional, descreve o trabalho como um de seus domínios pela suposta necessidade de racionalidade para desempenhá-lo.

Ao afirmar que as mulheres estão tomando conta de tudo, Edu demonstra ter constituído sua fala a partir da FD machista que tem um dos gêneros (o masculino) como o responsável, o que "toma conta" das coisas; entretanto esse discurso 'mesmo' está perturbado pelo simulacro de seu Outro, pois no simulacro as mulheres estão assumindo o papel que 'cabe aos homens'.

Em seguida Alex pergunta a Edu se a Malu o trocou por 'outro', manifestando, assim, uma visão da sexualidade vivida apenas na heterossexualidade. Ele nem cogita a hipótese de uma relação homossexual, ou seja, a FD machista silencia constitutivamente a igualdade entre os gêneros, assim como a homossexualidade. Edu confirma esse posicionamento do amigo ao afirmar "pior, por outra"; ou seja, é difícil ser traído, mas para Edu isso é ainda pior, pois ocorreu a partir de uma relação homossexual. Reitera ainda este ideal a reação de Alex, que até então, olhando para seu copo, aparentemente dá pouca importância ao caso do amigo. Alex põe as mãos na mesa, dá um salto na cadeira e encara o amigo arregalando os olhos, mostrando bastante espanto pelo fato de Malu estar com outra mulher.

Na sequência da narrativa, Edu relata que ele e a 'outra' estão competindo para ver quem fica com a Malu. Nesse momento tem-se mais um ponto de descentramento desse sujeito masculino identificado à FD machista. De acordo com Oliveira (2004), a tenacidade, a força e a potência necessárias à prática esportiva 
Produçäo de identidades e processos de SUBJETIVAÇä́ Em Práticas discursivas

são valores que se agregaram ao ideal moderno de masculinidade. Por mais que sejam deslocados pelos acontecimentos recentes, esses sujeitos ainda são atravessados por discursos oriundos de uma FD machista, mas apesar disso, esse homem (machista) vem descentrado pelo fato de ter como adversária uma mulher.

O fato de a amante de sua esposa se chamar Ricardinha também produz diferentes efeitos de sentido se considerada a historicidade desse termo: "Ricardão" tornou-se sinônimo de amante. A cena sugerida nesse programa foi semelhante: Edu chega de viagem e pega sua mulher na cama com outra, lugar comum ao "Ricardão" agora desempenhado por uma mulher. O relacionamento entre Malu e Ricardinha é sugerido como o estereótipo clássico de traição heterossexual. Até o nome da moça faz alusão ao do homem, quando nesse lugar: Ricardinha é o nome que designa essa mulher, mas, por associação a Ricardão, torna-se o nome genérico que pode se referir a qualquer amante do sexo feminino. A diferença aqui está na inversão do uso do sufixo: enquanto para o gênero masculino usa-se o aumentativo, para designar o gênero feminino usa-se o diminutivo, forma descrita como típica da variedade linguística do gênero feminino.

Alex repreende o amigo por estar ali no bar e questiona: "Quer perder a Malu por W.O.?" Essa discussão sobre a disputa amorosa é atravessada por termos próprios a um jogo, a uma competição esportiva. Edu afirma que ele e Ricardinha estão 'competindo' para ver quem fica com a Malu. Esse efeito de sentido culmina na representação de um estereótipo de homem machista ao confrontar a competitividade e racionalidade necessárias à prática esportiva (lidas pelo sujeito colocado numa FD machista) e a sensibilidade esperada pelas mulheres na relação amorosa (tradução que o discurso do 'senso comum' faz do discurso feminino). Dessa forma, tem-se a heterogeneidade 
do discurso presente no mesmo desse discurso e essa presença faz deslocar o sentido das memórias retomadas, produzindo o antagonismo próprio ao humor.

Com isso, delineia-se a segunda identidade de masculino dessa cena: enquanto Alex fala da FD machista com traços quase clichês de representação do seu discurso característico, Edu também é interpelado por essa FD; mas sua identidade também é constituída por traços do simulacro que a FD machista cria do feminino. Esse sujeito torna-se risível pelo antagonismo que essas vozes apresentam e pelo fato de ainda estar perdido.

Depois de relatados os problemas particulares que cada personagem vive nesse episódio, os quatro amigos começam a tecer considerações acerca das relações entre os gêneros. Ao dizer: "A verdade é que nós somos o chamado sexo frágil", Edu retoma o discurso de que a mulher é o sexo frágil, mas inverte essa relação. Tem-se aqui uma memória que é retomada, mas vem deslocada, como efeito da "tradução" feita pelo discurso machista da proposta de igualdade do discurso feminino e também como causa de humor. Agora são os homens que se identificam ao adjetivo frágil e à posição de sujeito que ele confere. Para o falante posicionado na FD machista, as melhores posições são propriedade do homem, portanto, qualquer tentativa de modificar esse estado de coisas desencadeia uma "revolução". O simulacro que esses homens criam do discurso feminino é sempre o estereótipo da feminista radical que visa a dominá-lo, e, consequentemente, a identidade que lhe caberia é a de homem inferiorizado.

Para reiterar essa posição os personagens citam dados que parecem seguir uma escala: vão do mais sério/científico ao mais chão/cotidiano. Por exemplo, "os números 
Produçäo de identidades e processos de subjetivaçäo em práticas discursivas

comprovam, as mulheres vivem $30 \%$ a mais que os homens" (científico), "elas odeiam rachar a conta" (cotidiano), "elas se depilam com nosso aparelho de barbear (cotidiano íntimo), "elas fingem orgasmos" (ápice da intimidade). Essas inserções de argumentos oriundos de diversos campos da convivência vão dando a amplitude desse fenômeno e contribuindo para o efeito humorístico do quadro. Tem-se aqui o destronamento tão caro à paródia: vozes/discursos se misturam, antagonizam-se e se ridicularizam.

Nesse caso, o destronamento ocorre em dois níveis: no primeiro, são ridicularizadas as relações estabelecidas entre os gêneros, ao serem mostradas em situações que se opõem; em seguida os sujeitos se identificam a esse cenário, afirmando: "Tá cada vez mais difícil fazer uma mulher feliz". Assim eles se colocam na posição-sujeito oferecida pela FD machista, que vê o macho como provedor, assumindo a função tradicional de satisfazer uma mulher; porém esse discurso mostra-se inadequado às situações vividas por eles. Tem-se, então, um sujeito que, colocado em lugar discursivo, verbaliza essa posição nos discursos que profere, mas se depara com uma conjuntura diferente, constituída sob uma nova ótica - calcada em discursos oriundos de outra FD: a da igualdade entre os gêneros.

Essa FD não pode ser compreendida tal como o é pelos sujeitos posicionados na FD machista. Eles a 'traduzem' como aquela que propõe a superioridade feminina e a inferioridade masculina. Novamente se está falando da interincompreensão polêmica dos discursos que possibilita a presença do discurso 'outro', o igualitário, no 'mesmo' machista que tenta circunscrevê-lo para delimitar sua identidade. 
Terceira parte :: Identidades do masculino no humor

O destronamento desse sujeito machista e sua identificação à posição-sujeito de sexo frágil são reiterados pela música de fundo: "Eu não sou cachorro, não", de Valdick Soriano.

Após esse momento os rapazes iniciam uma reação. Num ímpeto de coragem, Edu dá um murro na mesa, afirma que os homens têm valor e que pretende mostrar a superioridade masculina reconquistando Malu. O clima contagia: Beto se propõe a realizar com presteza as tarefas de manutenção da casa e Alex decide ser melhor que sua chefe no trabalho. Contagiados por esse espírito de revanche/superação, eles dão um viva aos homens.

Comessaatitude,poder-se-iaacreditarnumadesidentificação desses sujeitos com a posição-sujeito de inferiorizados que haviam assumido anteriormente e num movimento de retorno e identificação com um ideal clássico machista de masculinidade. Nesse caso, novamente se incorporariam a esses sujeitos os valores de bravura e coragem. Essa imagem é logo ridicularizada, pois eles ouvem barulho de tiro e todos eles gritam, sobem nas cadeiras, apavorados e tremem a ponto de derramar a cerveja dos copos.

Apesar do rompante de valentia no discurso verbal, as atitudes desses homens correspondem à representação do feminino como sexo frágil quando traduzido pelo discurso machista. Subir na cadeira gritando é um típico clichê da mulher frágil e medrosa que se assusta com baratas. Ironicamente, essa postura é assumida pelos sujeitos masculinos, que haviam acabado de se propor a mostrar às mulheres a superioridade e o valor dos homens. É interessante que o simulacro da igualdade, traduzido como "superioridade feminina" pelo discurso machista, exerce a 
função de inverter os papéis, passando o dominado a ser dominador, e vice-versa.

\section{Considerações finais}

A observação do discurso do/sobre o masculino nessa cena mostra que os sujeitos masculinos no discurso do programa são constituídos a partir de sua identificação com a FD machista. Eles colocam a superioridade e o domínio como características intrínsecas ao masculino e tentam desqualificar seu outro, o discurso da igualdade, negando-o. O funcionamento discursivo leva o sujeito a assumir um posicionamento e essa identificação impede o sujeito de compreender seu discurso outro tal como ele se constitui, possibilitando-lhe apenas criar um simulacro dele. Os indivíduos do programa criam um simulacro desse outro, leem-no como uma proposta de inversão dos papéis: o homem, de dominador da mulher, passa a ser dominado por ela.

Essa atribuição segue a ordem vigente pela visão machista: há um gênero que domina o outro, mas agora as posições são invertidas: o gênero dominante é o feminino e o dominado é o masculino. Essa inversão mostra, ao mesmo tempo, a criação de uma identidade de homem machista e a necessidade de o sujeito se desligar dessa identidade para conviver na sociedade atual. Isso torna esses personagens e suas identidades risíveis, e no discurso do programa encontra-se um 'velho homem' destronado, subvertido ou um novo homem ainda perdido, que não sabe como agir. É nesse contexto que o homem se vê como inferiorizado, - portanto, como o sexo frágil. 
Terceira parte :: Identidades do masculino no humor

\section{Referências}

AUTHIER-REVUZ, J. Hétérogeneité montrée et hétérogeneité constitutive: éléments pour une approche de láutre dans lê discours. In $D R L A V$ - Revue de linguistique, n. 26, Paris, 1982.

ALVES, B. M.; PITANGUY, J. O que é feminismo. São Paulo: Brasiliense, 1985.

BERGSON, H. O Riso. Tradução de Nathanael C. Caixeiro. 3. ed. Rio de Janeiro: Zahar, 1983.

CHARAUDeAu, P.; MAINGUENEAU, D. Dicionário de Análise do Discurso. São Paulo: Contexto, 2004.

FOUCAULT, Michel. Microfísica do poder. Rio de Janeiro: Graal, 1999.

HALL, S. A identidade cultural na pós-modernidade. Tradução: Tomaz Tadeu Silva e Guacira Lopes Louro. Rio de Janeiro: DP\&A, 1997.

MAINGUENEAU, D. Gênese dos discursos. Curitiba: Criar, 2007.

OLIVEIRA, P. P. A construção social da masculinidade. Belo Horizonte: Editora UFMG; Rio de Janeiro: IUPERJ, 2004.

POSSENTI, S. Os Humores da língua. Campinas: Mercado de Letras, 2000.

SALIBA, E. T. Raízes do riso - a representação bumorística na bistória brasileira: da Belle Époque aos primeiros tempos do rádio. São Paulo: Companhia das Letras, 2002.

SANT'ANA, A. R. de. Paródia, paráfrase \& cia. São Paulo, Ática, 2002. 
